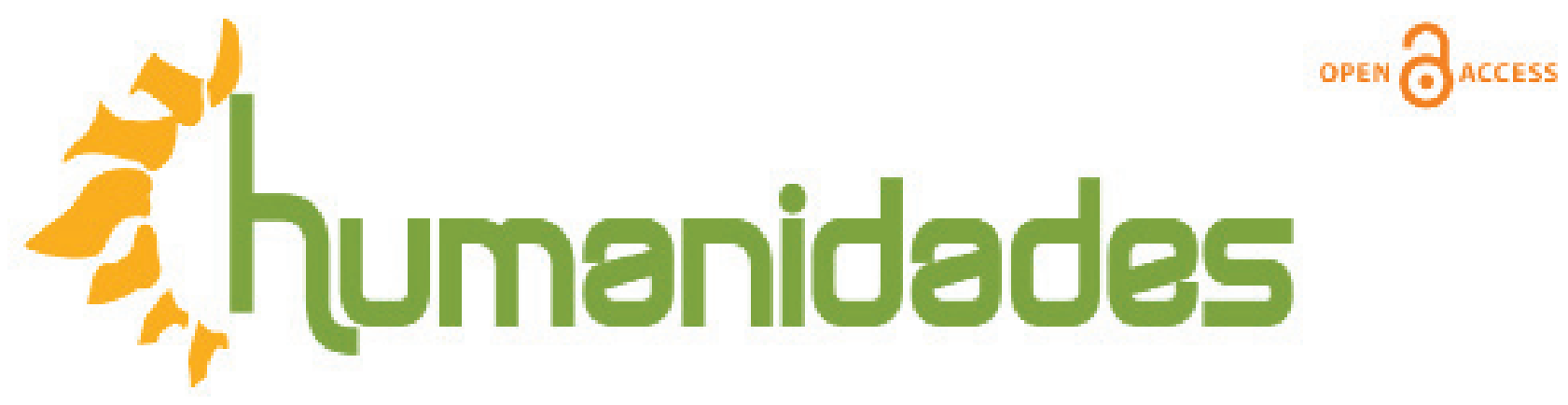

Revista de la Escuela de Estudios Generales, Universidad de Costa Rica

Enero-julio, 2019 •Volumen 9, número 1 • EISSN 2215-3934•pp. 1-26

Recibido: 31-Octubre-2018 Aceptado: 13-Noviembre-2018

\title{
Cuerpos, imágenes e identidades. Sobre filosofía, arte y transformación social
}

DOI: https://doi.org/10.15517/h.v9i1.35344

\section{Yera Moreno Sainz-Ezquerra}

Doctora en Filosofía. Profesora en la Facultad de Bellas Artes de la Universidad Complutense de Madrid, España.

Correo electrónico: yeramoreno@hotmail.com

Todos los derechos reservados. Universidad de Costa Rica. Esta revista se encuentra licenciada con Creative Commons. Reconocimiento-NoComercial-SinObraDerivada 3.0 Costa Rica. Correo electrónico: humanidades@ucr.ac.cr/ Sitio web: http: //revistas.ucr.ac.cr/index.php/ humanidades 


\section{Cuerpos, imágenes e identidades. Sobre filosofía, arte y transformación social}

\section{Resumen}

El presente artículo propone abordar el campo del arte como un espacio posible para la transformación social. Con base en la capacidad performativa de las imágenes, y en los procesos de articulación de los sujetos y las identidades, se presentan diferentes prácticas artísticas que, desde una perspectiva feminista y queer, proponen nuevas narrativas visuales que subvierten y transforman los imaginarios hegemónicos sobre los cuerpos, el deseo y las identidades. A partir de autoras como Judith Butler o Chantal Mouffe y de la articulación teórica que realizan en relación a la identidad desde una perspectiva antiesencialista, se retomarán ciertos conceptos (como los de performatividad, reapropiación o citacionalidad) que han permitido la reformulación de la subjetividad en nuevos términos políticos y sociales y han permeado en el trabajo visual de toda una diversidad de artistas contemporáneos. Se analizarán, para ello, diferentes propuestas que, situadas en el campo de las artes visuales y a través de diversos formatos (como la fotografía o la pintura mural), han irrumpido en los últimos años en los imaginarios dominantes y han supuesto una reestructuración del paisaje simbólico en lo relativo a cuestiones como el género, la racialidad, el sexo, la sexualidad o el deseo. 


\title{
Bodies, Images and Identities. On Philosophy, Art and Social Transformation
}

\begin{abstract}
This article proposes to approach the field of art as a possible space for social transformation. Focusing on the performative capacity of images, and on the articulation processes of subjects and identities, different artistic practices are presented that propose new visual narratives that subvert and transform hegemonic imaginaries about bodies, desire and identities from a feminist and queer perspective. From authors like Judith Butler or Chantal Mouffe and the theoretical articulation they make in relation to identity from an anti-essentialist perspective, certain concepts (such as performativity, reappropriation or citationality) will be retaken, which have allowed the reformulation of subjectivity in new political and social terms and have permeated the visual work of a diversity of contemporary artists. For this purpose, different proposals will be analyzed. These proposals, located in the field of visual arts and through various formats (such as photography or mural painting), have burst in recent years in the dominant imaginaries and have involved a restructuring of the symbolic landscape with regard to issues such as gender, raciality, sex, sexuality or desire.
\end{abstract}




\section{Las identidades desde una perspectiva antiesencialista}

Dado que uno de los objetivos principales de este artículo es abordar el campo del arte como un territorio posible para la transformación social, con relación a la producción de identidades y sujetos contrahegemónicos, comenzaremos perfilando algunas claves teóricas para la reflexión sobre esta producción desde una perspectiva antiesencialista. Estas claves y conceptos teóricos nos servirán de metodología para el análisis crítico de las obras artísticas propuestas. Para ello nos basaremos en autoras cuyo trabajo ha estado centrado en la reformulación de la identidad desde esta perspectiva, como lo son Chantal Mouffe y Judith Butler, y en algunas de sus tesis fundamentales, como la noción de "exterior constitutivo" o la idea de una "ontología del cuerpo como ontología social". Introducir estas ideas en relación con el sujeto y las identidades nos permitirá analizar diferentes prácticas artísticas que nos ofrecen nuevos modelos contrahegemónicos de sujetos, cuerpos e identidades en torno a los cuales vamos articulando nuestra propia subjetividad. El arte se mostrará así, como veremos a lo largo de estas páginas, como un terreno excepcional para la transformación social, ya que en él se producen nuevos imaginarios que reconfiguran lo real y que nos ofrecen modelos posibles conforme a los cuales vamos produciendo nuestra propia identidad.

Abordar el análisis de la producción de la subjetividad desde una perspectiva antiesencialista implica considerar al sujeto como múltiple, abierto, cambiante, con una identidad no fijada por completo, sino en constante proceso de (re)articulación y, además, implica considerar la diferencia como una pieza clave en la constitución de cualquier identidad. Para autoras cuyo trabajo se sitúa desde esta perspectiva, el sujeto quedará reformulado en términos performativos (en el caso de Butler) o en cuanto a prácticas articulatorias que cristalizan de manera contingente en unas "posiciones de sujeto" abiertas a nuevas rearticulaciones (en el caso de C. Mouffe). 
En ambas propuestas, podemos considerar la identidad como "inventiva y móvil, no es algo que sucedió y se quedó anclado para siempre, sino algo que se va construyendo y se rehace constantemente" (Cortés, 2000, p. 17) en relación con un afuera constitutivo.

Por tanto, lo que se plantea para el análisis que se desarrolla a lo largo de este artículo es una consideración de la identidad alejada de posiciones esencialistas, a la par que se propone abordar el terreno del arte como ese afuera constitutivo conforme al cual podemos ir articulando nuestra propia subjetividad e identidad (ya sea individual o colectivamente). De este modo, el arte se nos ofrece como un espacio posible para la transformación social, pues en él, y a través del trabajo con la imaginación y la creación de ficciones, pueden producirse nuevas narrativas visuales contrahegemónicas sobre el sujeto y la identidad. Una de las nociones que en este sentido resulta especialmente interesante rescatar es, por ello, la de "exterior constitutivo".

La noción de "exterior constitutivo", tomada del pensamiento desarrollado por J. Derrida (como se citó en Mouffe, 2005, p. 22), será una de las ideas claves entre autoras como C. Mouffe o J. Butler, cuyo trabajo en relación con las identidades se sitúa desde esta perspectiva antiesencialista. Para ambas autoras, esta noción les permite repensar las identidades y el sujeto desde una perspectiva antiesencialista en la que la identidad se articula siempre en relación a una exterioridad que la constituye y que impide su cierre completo, lo que implica su apertura a nuevas rearticulaciones. La exterioridad constitutiva hará referencia, por ello, a una perspectiva según la cual las identidades son consideradas abiertas, móviles y no suturadas por completo. El sujeto se configura en relación con un afuera que, sin embargo, no es ajeno a él, sino que lo constituye: nos constituimos gracias a este exterior, de forma que sin él no sería posible la articulación de ninguna identidad. Solo marcando un exterior se constituye la propia identidad, que nunca queda cerrada por completo, pues está en relación recíproca con esa exterioridad. Así, una de las características fundamentales de la identidad será su "incompletitud", ya que siempre es dependiente de un exterior que la constituye sin llegar a lograr nunca su sutura completa. 
Si pensamos esta noción de exterioridad constitutiva con relación al tema que nos ocupa sobre la transformación social, lo interesante será ver cómo esa no sutura de las identidades es lo que permite, precisamente, su movilización social o, lo que es lo mismo, su transformación. Pues es esta no sutura la que posibilita que las fronteras entre la exterioridad (constitutiva) y la identidad sean móviles y vayan cambiándose y desplazándose. Así, esta apertura constituyente es la que permite la posibilidad de nuevas rearticulaciones que impiden la fijación completa de sujetos e identidades y "desvela lo que está en juego en la constitución de la identidad" (Mouffe, 2009, p. 89).

La noción de exterior constitutivo remite, asimismo, a que toda identidad se constituye siempre en relación a lo diferente, a lo que no es ella pero que, por otra parte, hace posible su articulación. Esta relación con lo diferente será, por tanto, constitutiva de la identidad, y el dualismo quedará reformulado entre diferenciamismidad, pues lo propio de la identidad será su constitución en relación a lo exterior/diferente a ella misma. Si la identidad nunca es completamente cerrada sobre sí misma, puesto que está abierta a un exterior que la constituye, todo objeto llevará inscrito, en la configuración de su identidad, algo distinto de sí mismo: el exterior al que está abierto y que construye y posibilita su propia identidad. En este sentido, J. Butler afirma que "la diferencia es la condición de posibilidad de la identidad, o mejor, su límite constitutivo: lo que hace posible su articulación $y$, al mismo tiempo, lo que hace imposible cualquier articulación final o cerrada" (Butler, 2000, p. 113). Además, en el caso de J. Butler, es especialmente interesante poner esta noción de exterioridad constitutiva en relación con su propuesta de la identidad en términos performativos y con una de sus tesis claves según la cual “toda ontología del cuerpo es una ontología social” (Butler, 2010, p. 3).

La propuesta butleriana respecto a la subjetividad operará ciertos cambios fundamentales respecto a la manera de entender la materialidad del cuerpo. Uno de estos cambios será la consideración de que los cuerpos, nuestros cuerpos, se constituyen socialmente. Así, para J. Butler, el cuerpo, puesto que adquiere su inteligibilidad con otros, ya que su materialidad es "modelada" según las normas que aprendemos con otros cuerpos, se constituye socialmente, se articula como cuerpo en compañía de otras(os) y por la interpelación de esos otras(os) que le reconocen como cuerpo legítimo. 
La materialidad del cuerpo, por tanto, es constituida socialmente, lo que revela la exposición continua del cuerpo a los otros, en cuya compañía se va articulando. Esta exposición es lo que hace que todos los cuerpos, constituidos según normas sociales (de género, de sexo, de sexualidad, de capacitismo o de racialidad, entre otras), sean vulnerables. Así, Butler insistirá, retomando las tesis de A. Cavarero, en que "somos, por necesidad, seres expuestos unos a otros" (Butler, 2005, p. 31). Y esta exposición a las(os) otras(os) indica, a su vez, que el cuerpo, todos los cuerpos, tienen "invariablemente una dimensión pública" (Butler, 2006, p. 21); se constituyen públicamente, atravesados y conformados por normas que encarnamos junto con otros cuerpos y para otras(os). Es en esta esfera de lo público, que atraviesa las actitudes, deseos, sentimientos y relaciones consideradas privadas, en la que negociamos el propio cuerpo, el género, el sexo y la sexualidad. La dimensión pública del cuerpo apunta también a la negociación, a la apropiación de la norma y a las posibilidades de desplazarlas, puesto que el propio cuerpo "toma forma mediante una negociación temporal y espacial específica" (Butler, 2010, p. 53). Negociamos con otros cuerpos las normas que hacen legibles nuestros propios cuerpos, que les dan una forma "humana", y en esta negociación, en el proceso en que el cuerpo - generizado, sexualizado, racializado — va articulándose y rearticulándose como tal, hay posibilidad de desplazamiento de las normas sociales que, precisamente, le han dado su inteligibilidad.

Lo interesante de ambas consideraciones, tanto de la noción de exterior constitutivo como de la dimensión pública del cuerpo, por lo que suponen para la producción de las identidades, es que en lo relativo al diálogo con el terreno de las prácticas artísticas ambas nociones nos permiten abordar el arte como un posible "exterior constitutivo" para la articulación de la identidad y, en este sentido, como esa dimensión pública en la que se negocian nuestras nociones de cuerpo, de sexo, de género, de capacitismo o de racialidad. Esto nos sirve no sólo para abordar el análisis de las prácticas culturales como un contexto público en el que nuestro cuerpo, nuestro género o nuestra identidad son negociados y (re)negociados, sino, sobre todo, para atender a las posibilidades que pueden abrirse en dicho terreno, puesto que se trabaja con la imaginación y la ficción, para abrir disensos y producir desplazamientos en esas configuraciones hegemónicas de sujeto e identidad conforme a las cuales articulamos la nuestra. 


\section{Cuerpos, imágenes y performatividad}

Atender a las posibilidades que el arte puede ofrecernos de imaginar nuevas reconfiguraciones de lo real revela la capacidad de acción de las imágenes y, en este sentido, implica atender a su estatus "performativo", a esos "usos performativos" (Fernández, 2012) que generan realidad, que producen lo real más que representarlo $\mathrm{o}$, más bien, que en su representar, hacen lo real y actúan en dicha realidad. Me interesa, por ello, que desplacemos la definición del performativo ${ }^{1}$ de ese decir que significa hacer, al campo del arte, para así encontrarnos con un re-presentar (con un imaginar, con un ficcionar) que hace, y que, en ese acto de hacer, puede intervenir en lo real y modificarlo. Por ello, atender a este "giro performativo" implica "comprender que las imágenes no solo representan, sino que deben entenderse, además, como agentes con posibilidad de trascender su propia posición dentro o fuera del archivo dominante" (Vogel, 2011, p. 22). Si entendemos por archivo ese imaginario colectivo en torno al cual nos movemos, comprendemos, conocemos el mundo y nos comprendemos y articulamos a nosotras y nosotros mismos, la capacidad de acción de las imágenes para "trastocar" el archivo dominante se refiere a su hacer en la propia realidad, a su producción de realidad.

Esto conlleva comprender, a su vez, que una imagen (una obra, una palabra, un cuerpo) nunca actúa aisladamente, sino dentro de un entramado complejo de otras muchas imágenes (cuerpos, palabras) al que llamamos imaginario y que conforma nuestro mapa simbólico de lo real. Es en su posición dentro (o fuera) de ese contexto cultural donde radica su función pública y su capacidad de acción, de posible movilización de ese dispositivo visual al cual pertenecen, que puede ser transformado con su nuevo decir. Es por ello que "una imagen nunca va sola" (Rancière, 2010, p. 101), remite a otras muchas imágenes, ya sea para legitimarlas o para subvertirlas; cita y repite esas otras imágenes, por eso reconocemos esa nueva imagen que nos llega y, por eso mismo, en dicha repetición, puede subvertirse la cadena de citación visual en la que se inserta. 
Recordemos, en este sentido, que para J. Butler la "agencia" surge en ese proceso performativo en el que el sujeto va articulándose, es decir, en la cita y repetición de las normas que nos constituyen como sujetos. La agencia - o capacidad de acción-, desde esta perspectiva, es parte del propio proceso performativo (de hecho surge en ese "fracaso" del performativo en la citación), pues es al actuar, al citar, al repetir cuando se producen los desplazamientos y los márgenes para subvertir y transformar la cadena de citación en la cual nos vamos conformando. Del mismo modo, la capacidad de acción de las imágenes remitiría a estas citaciones performativas, a una cadena de imágenes comunes (de cuerpos, de modos de ser, de estar, de formas de ver) que nos preceden, que repetimos en otra imagen, pero en cuya repetición pueden producirse desplazamientos, lo cual causa que entren en juego otras ficciones, se generen otros códigos que rompen con esa cadena de visibilidad y la movilizan y se provoquen interferencias. En definitiva, "todo lenguaje, todo discurso, todo aparecer de un cuerpo ante otro, está sujeto a la citacionalidad. Lo relevante es que cada citación, cada nueva aparición, tiene el potencial de introducir lo inédito, pues en ella está implícito lo incalculable” (Garbayo Maeztu, s.f., p. 22).

No es de extrañar, por ello, que la repetición y la reapropiación sean estrategias comunes utilizadas por muchas y muchos artistas para desplazar los imaginarios hegemónicos. Ambas estrategias se sirven de esa citacionalidad de las imágenes que produce el archivo para provocar grietas subversivas en dichas cadenas citacionales. Para ello, utilizan la repetición (de imágenes conocidas, pertenecientes a los archivos dominantes) para reapropiarse de ellas, subvirtiendo con dicho gesto la genealogía normativa que da sentido a dichas imágenes y convirtiéndolas en contrahegemónicas. Recordemos, no en vano, que la "estructura citacional del performativo convierte la reapropiación y la resignificación en la inevitable posibilidad de producir efectos inesperados" (Pérez, 2007, pp. 373-374). Proponemos, por ello, a partir de este marco teórico, analizar ciertas prácticas artísticas que desde contextos geopolíticos muy diferentes, y abordando temáticas distintas, se centran en estas reapropiaciones de los archivos visuales dominantes para activar desplazamientos en dichos imaginarios y generar contrahegemonías visuales en relación a la sexualidad, el género, la colonialidad, la racialidad, entre otros. 


\section{Reapropiaciones desde el archivo y sus desplazamientos}

Para ello comenzaremos con el artista Alexis Esquivel y, en particular, con su obra Memorial Garden ${ }^{2}$ (ver las figuras 1 y 2 pertenecientes a dicho proyecto) como un ejemplo de esta articulación de un archivo contrahegemónico que se reapropia de códigos y narrativas visuales existentes para desplazarlas, en este caso trabajando con la pintura de historia, pero desde una perspectiva decolonial crítica y enfocada a la racialidad. Si la pintura de historia puede ser considerada como el denominado "gran género dentro del canon de la pintura académica" (Sánchez, 2015, p.272), dicho género ha estado ligado ideológicamente a la formación del Estado Nación en occidente, como Suset Sánchez señala y, por ello, se relaciona de manera directa con los procesos de colonización llevados a cabo por los países europeos en los territorios de América Latina. Esquivel, interesado en este género pictórico y en dichas relaciones ideológicas con la colonización, subraya, a través de su obra, la construcción de dichos discursos coloniales de la historia, contada desde occidente, en los que se hacen evidentes problemas como el racismo o las ausencias y objetualizaciones de los cuerpos racializados en las narrativas visuales de la historia del arte occidental. Para ello, el artista trabajará con lienzos de gran formato, dentro del género de pintura de historia y sus códigos de visualidad, pero para contar esas otras imágenes — esas otras historias - que la narrativa visual occidental ha desechado en sus márgenes.

Así, "las imágenes de Esquivel se construyen desde las zonas de contacto de las diásporas y del forcejeo postcolonial donde se cruzan las historias de España y Cuba" (Sánchez, 2015, p.272). En sus obras, el artista representará, para ello, escenas cotidianas que aparecen en los medios de difusión sobre episodios de la vida política de la actualidad, cuestionando las "ausencias en las representaciones nacionales de voces subalternas como las de los afrodescendientes" (Sánchez, 2015, p.272). 
Con dicho gesto, el artista irá generando toda una serie de contrarrelatos visuales, situados desde la crítica postcolonial a los regímenes de visualidad occidentales y a las ausencias sobre las que se asientan dichos regímenes, pero trabajando con un género pictórico y con una forma de narrar que surgen vinculados directamente a los procesos de colonización.

A través de esa citacionalidad visual y su repetición, pero provocando importantes desplazamientos en dicha repetición (en cuanto a lo que se cuenta en los lienzos de Esquivel), el artista logrará revisar y poner en cuestión "las imágenes del poder simbolizadas tradicionalmente en el género de la Pintura de Historia" (Sánchez, 2015, p. 272). En palabras del propio Esquivel: "me aprovecho de la pintura para construir discursos críticos. En cierto modo, me gusta pensar los cuadros como un tipo de terrorismo, cuando metes el cuadro dentro de la casa del galerista o del coleccionista y siempre hay contenidos críticos, que incluso pueden ir en contra de los propios sujetos que han adquirido la pieza" (en entrevista realizada por Suset Sánchez, en Sánchez, 2015, p. 275). Dicha construcción crítica, producida dentro de unas narrativas visuales hegemónicas, provocará, sin embargo, un archivo visual decolonial, pero mediante la utilización de un género, el de la pintura histórica, ligado a la producción del propio colonialismo.

\section{Figura 1.}

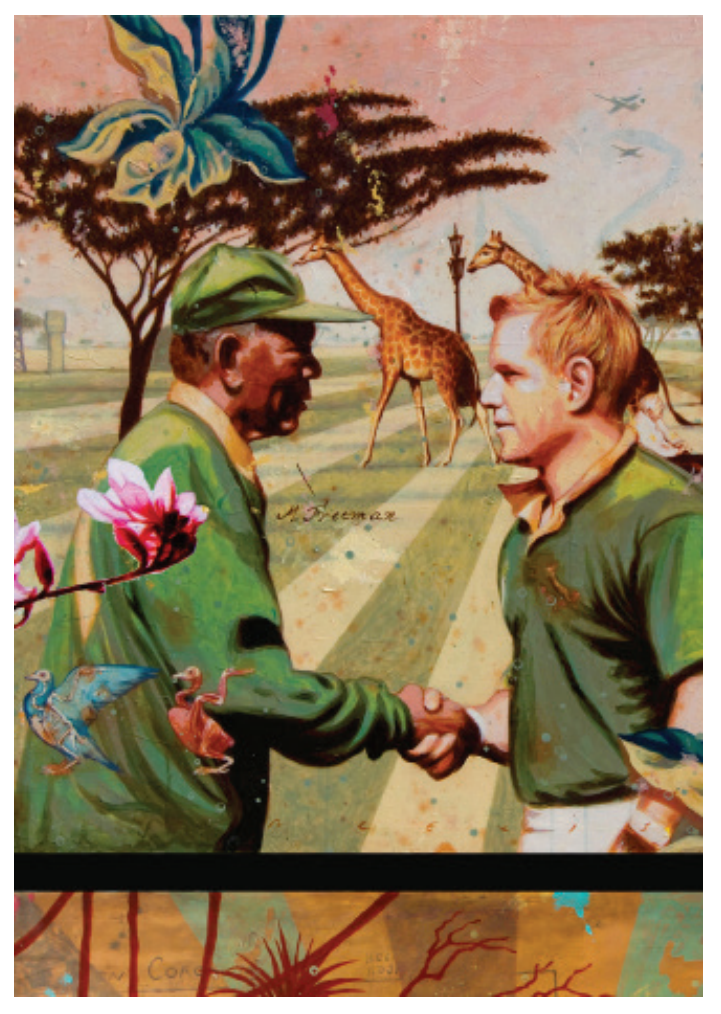

Perteneciente al proyecto Memorial Garden, Alexis Esquivel. 


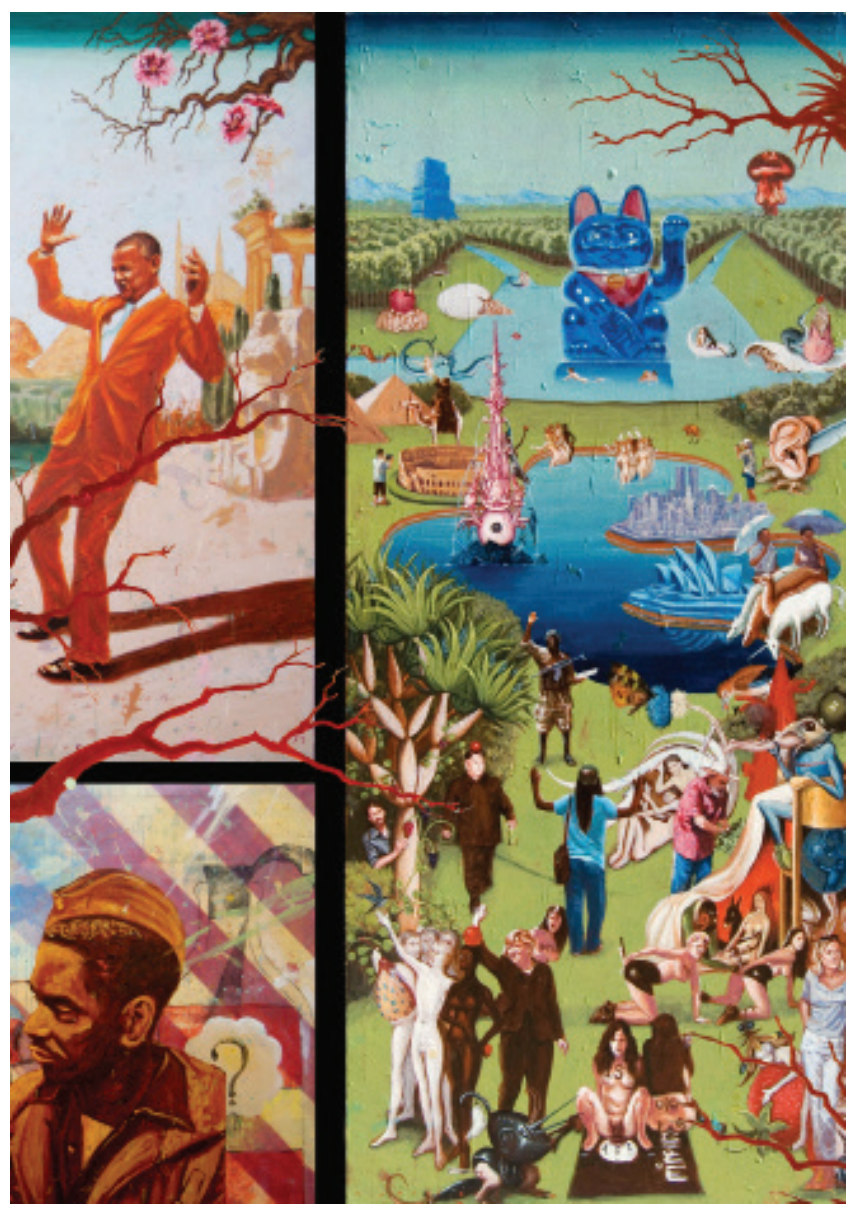

Figura 2. Perteneciente al proyecto Memorial Garden, Alexis Esquivel.

En una línea similar en cuanto a la (re)apropiación de un archivo visual existente, en este caso el del cine mainstream, y desde una perspectiva de la disidencia sexual, encontramos a las artistas Cabello/Carceller. Las artistas Cabello/Carceller trabajan juntas desde la década de los noventa en torno al cuestionamiento y la subversión de las normativas de género/sexo/sexualidad, prestando especial atención a la construcción y posible desplazamiento de los modelos de masculinidad en el imaginario dominante y ocupándose, especialmente, de los procedentes del mundo del cine. Su trabajo, jugando con formatos tan variados como el audiovisual, la fotografía o la performance se ha ocupado, desde una posición feminista y queer, del género, el sexo y la sexualidad en clave performativa, poniendo especial énfasis en los desplazamientos en ese ritual performativo a través de la repetición de gestos, miradas, actitudes, movimientos, formas de andar, de seducir y de posar. 
Conscientes del poder de las imágenes procedentes del mundo del cine y de los medios de difusión en la construcción y legitimación de modelos de masculinidad y feminidad, las artistas, a través de diferentes estrategias creativas que a menudo pasarán por el formato fotográfico y audiovisual, aprovecharán esas brechas y fracasos de la citación performativa para desplazar las normas de género, sexo y sexualidad y generar otros sujetos que rompan con las lógicas binarias hegemónicas y que generen todo tipo de ambigüedades. Así, Cabello/Carceller trabajarán con esas imágenes que se repiten, con esa cadena de citaciones visuales que vemos continuamente y que articulan la masculinidad y la feminidad. A través de la repetición de escenas, de gestos, de miradas y de su (re)apropiación por parte de otros cuerpos, Cabello/Carceller indagarán en sus trabajos sobre el carácter imitativo del género, esas copias de copias sin original de las que nos hablara J. Butler, haciendo que miremos a esas miles de imágenes que construyen nuestra subjetividad generizada y produzcamos otras copias, aparentemente iguales, pero en las que ya se han producido ciertos desplazamientos.

Siguiendo con su línea de trabajo crítica sobre los modelos de masculinidad procedentes del mundo del cine, en el proyecto Archivo: Drag Modelos (ver figuras 3,4 y 5 pertenecientes a la serie), las artistas proponen, a través de la producción de un archivo fotográfico que juega con el "desplazamiento" y la reapropiación, la articulación de nuevos sujetos del imaginario del cine. Las fotografías que resultan del proyecto se apropian así de las imágenes del cine para modificar a los sujetos de esas imágenes que configuran nuestro imaginario de cuerpos, de deseos, etc. Como en otras ocasiones, las artistas abrirán una convocatoria en la que invitarán a mujeres a participar en el proyecto. Estas participantes, las modelos del proyecto, se convertirán en los sujetos de este nuevo imaginario. Cada una de las participantes encarnará a uno de sus héroes masculinos del cine. A través de una cuidada selección de los lugares y los escenarios para la producción de estas escenas fotográficas, se recrearán fotogramas de películas en los que aparezcan cada uno de los héroes masculinos elegidos por las participantes: James Dean (figura 3), Ennis del Mar, Marlon Brandon (figura 4), John Travolta, Vin Diesel (figura 5), Brad Pitt, entre otros. 
En dichas "reactuaciones" fotográficas, las mujeres participantes ocuparán el lugar de su héroe, convirtiéndose, al imitar la pose, el gesto, la posición y al recrear esas nuevas escenas, en los sujetos de esas narrativas visuales tomadas del imaginario dominante. Las participantes del proyecto dejarán su posición de espectadoras "fuera de la pantalla" para pasar a estar dentro de la ficción visual, a ser protagonistas de la acción y, con este desplazamiento, las imágenes habrán quedado igualmente desplazadas y subvertidas por esos otros cuerpos que antes miraban desde fuera. Mediante esta apropiación de esas imágenes-escenarios que sitúa en ellos a otros sujetos/cuerpos, las artistas estarán ya subvirtiendo esas imágenes, que quedan desplazadas al situar en ellas otros sujetos de la acción. La fotografía funcionará, así, como "una forma de memoria y, sobre todo, de posibilidad; un medio que, además de representar, genera una realidad" (Vogel, 2011, p. 26). Así, la capacidad de acción de estas imágenes surge, precisamente, en la apropiación de una repetición, en esas brechas que aparecen al repetir y citar y que son ocupadas por otros cuerpos; es en esa repetición de imágenes que tenemos vistas, que son compartidas dentro de la cultura visual dominante, que son a menudo citadas, donde emerge la posibilidad de desplazar la imagen normativizada y normalizada.

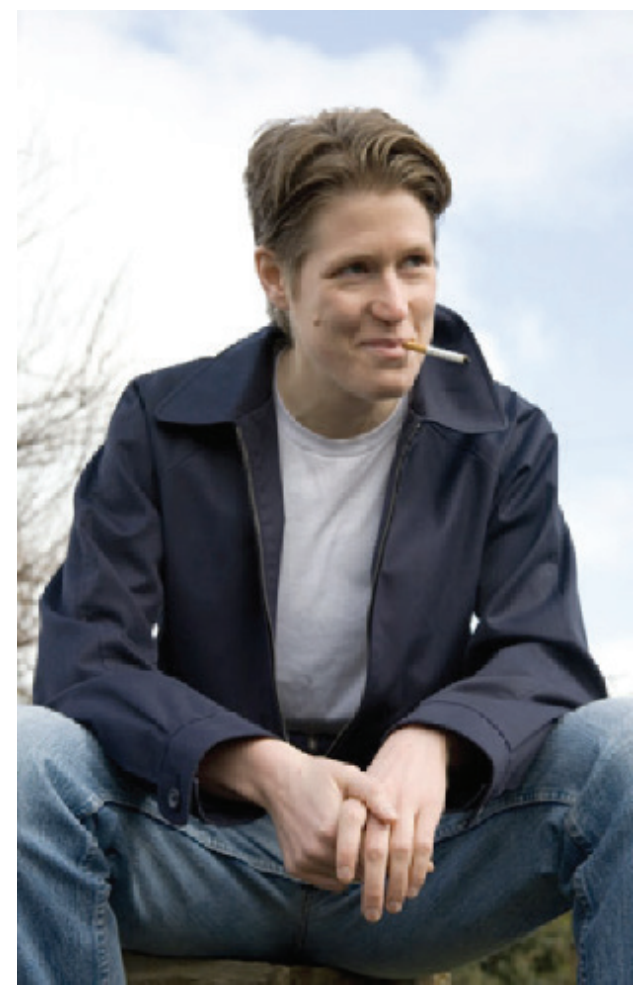

Figura 3. Perteneciente a la serie Archivo Drag Modelos, Cabello/Carceller. 
Cuerpos, imágenes e identidades...

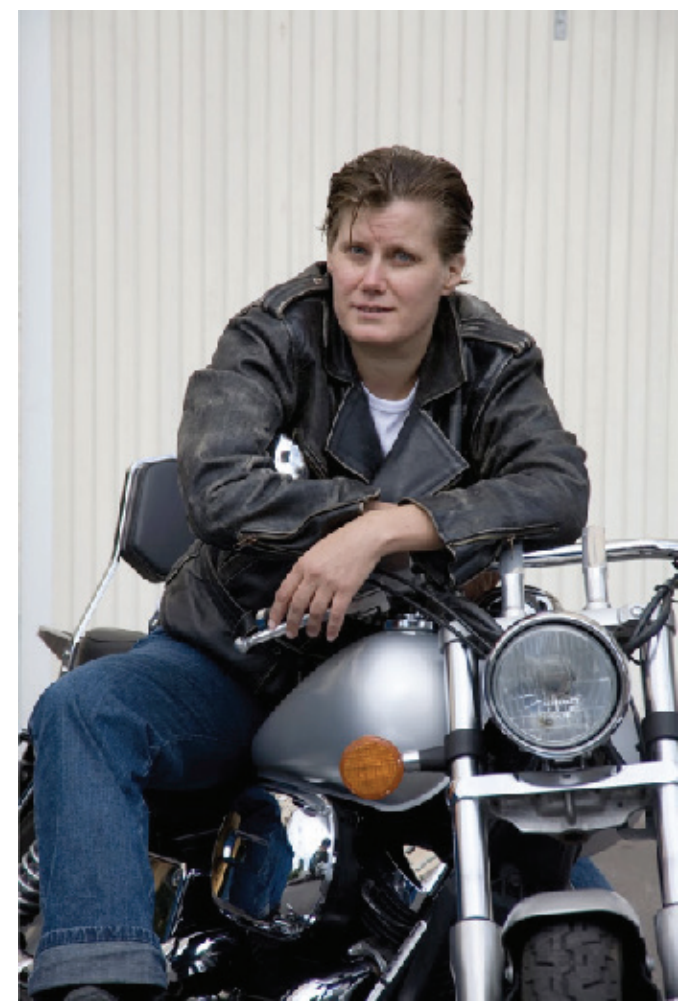

Figura 4. Perteneciente a la serie Archivo Drag Modelos, Cabello/Carceller.

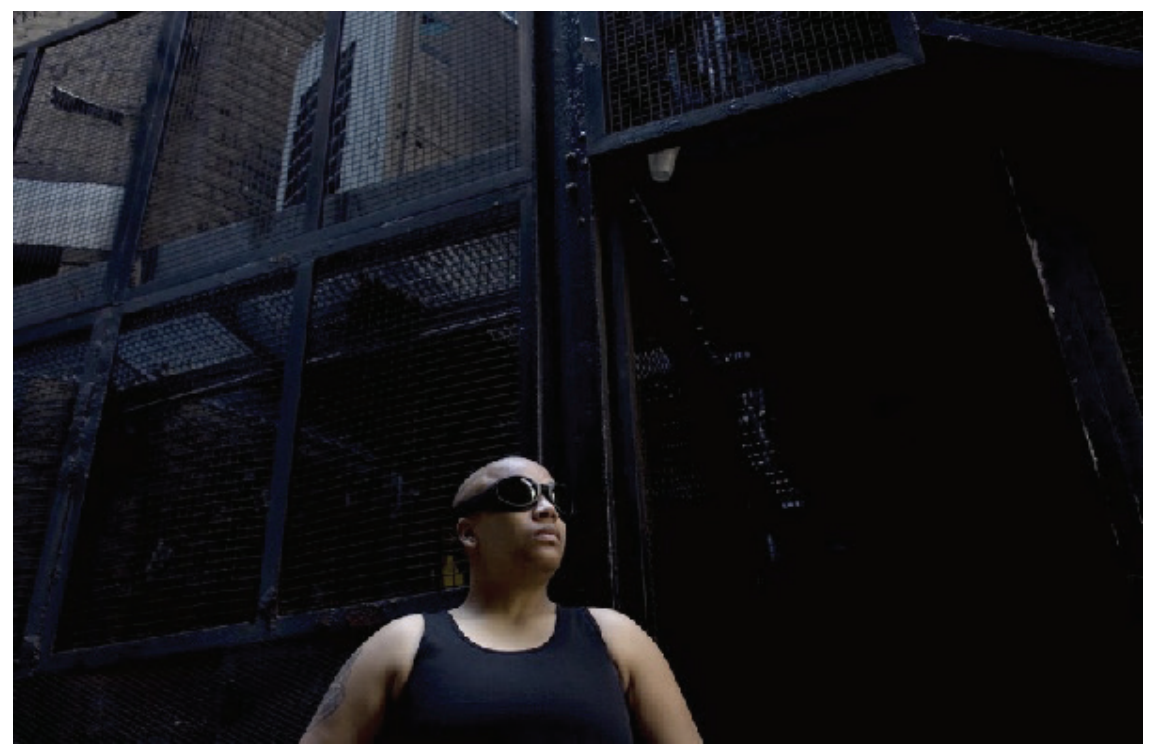

Figura 5. Perteneciente a la serie Archivo Drag Modelos, Cabello/ 
También la propuesta de la artista Carmela García girará en torno a la(re)articulación de archivos visuales y su desplazamiento. Su trabajo alude al estatus de la fotografía como generadora de ficciones y al modo en que estas ficciones irrumpen en los marcos delorealyloreconfiguran.Podemos, así, analizarmuchas desusimágenesfotográficas como ficciones visuales que, sin embargo, remiten directamente a la fotografía como productora de realidad. Uno de sus proyectos, Mujeres, amor y mentiras ${ }^{3}$, es especialmente interesante por cuanto supone la producción de una ficción por parte de la artista que reescribe el imaginario dominante y sus narrativas visuales. Concebido a modo de foto libro y compuesto por dos partes, la primera de ellas se compone de una selección de fotografías que forman parte de la colección que la artista lleva haciendo desde hace años bajo el título de "Mujeres enamoradas" (ver figuras 6 y 7 ).

Para articular esta colección, la artista comenzó a comprar y coleccionar fotos antiguas, en su mayoría anónimas, en las que aparecían mujeres en pareja o en grupos en actitud cariñosa o en un "momento entrañable" (García, 2003). Más allá de la historia "real" de cada una de las fotos que Carmela García iba recopilando, la elección de la artista para cada foto atendía a su decisión de si las protagonistas de la foto estaban enamoradas (y pasaban así a formar parte de la colección) o no, en cuyo caso eran excluidas de la misma. Así, es la propia artista, con su gesto, su elección y su mirada, la que dota de una nueva narrativa a cada una de esas fotografías. No importa lo que la fotografía originariamente estuviera contando (si esas mujeres eran amigas, hermanas, primas, compañeras, amantes o parejas), sino que es la artista quien, con su gesto de agruparlas bajo ese título de "Mujeres enamoradas", hace que dichas fotos se conviertan en lo que son ahora y hayan pasado a contar otra historia. La artista, de manera intencionada, articula así otra narrativa de la foto, desplazando las historias del origen que las fotos pudieran estar "representando" por las nuevas historias que ahora cuentan, gracias a su mirada. Es esta intencionalidad, este agrupamiento, selección y reubicación de las imágenes bajo la colección de la artista, lo que hace que emerja otra historia y que se cree una nueva "ficción narrativa" que subvierte las intenciones y los usos originarios que las fotos pudieran tener. 
En este sentido, la artista afirmará: “cambié el espacio objetivo de su origen por el subjetivo de mi mirada para así poder contar otra historia" (García, 2003). Y es esta reapropiación a través de la mirada de la artista lo que implica, en este caso, la emergencia de un nuevo imaginario que si bien parte de imágenes que ya existían, no lo hacían en el sentido en el que nos las presenta ahora la artista. Todo ello implica que toda imagen, a pesar de su uso o intención originaria, puede ser (re)apropiada para subvertir, incluso, ese uso originario que le dio existencia y que podría atender a dar legitimidad social al discurso hegemónico. Lo que nos recuerda que en toda citación performativa es posible la (re)apropiación y, con ello, el desplazamiento de las normas que citamos y repetimos. El gesto de Carmela García, provocado por un nuevo mirar intencionado, es el que hace posible que aparezcan nuevos sujetos que, aunque estaban dentro de la foto, no existían en ella bajo la narrativa originaria que la foto contaba.

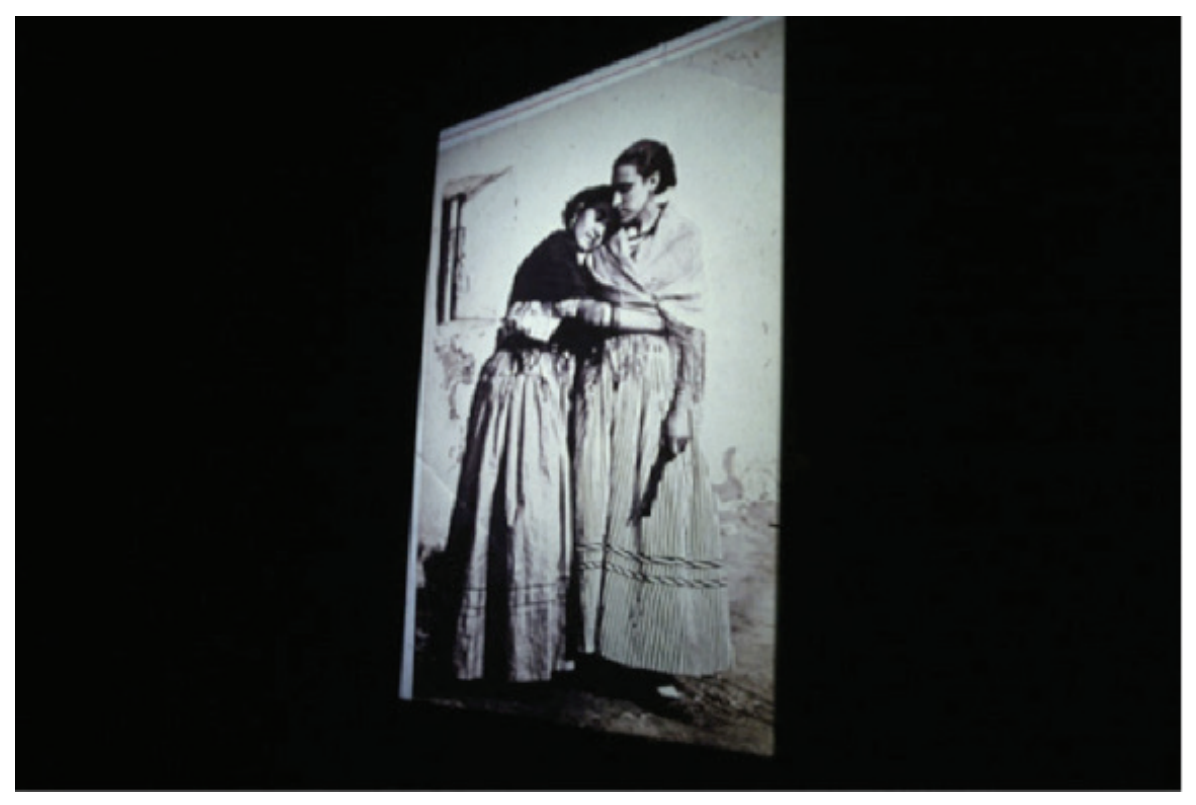

Figura 6. Mujeres, amor y mentiras, Carmela García. Imagen de instalación. 


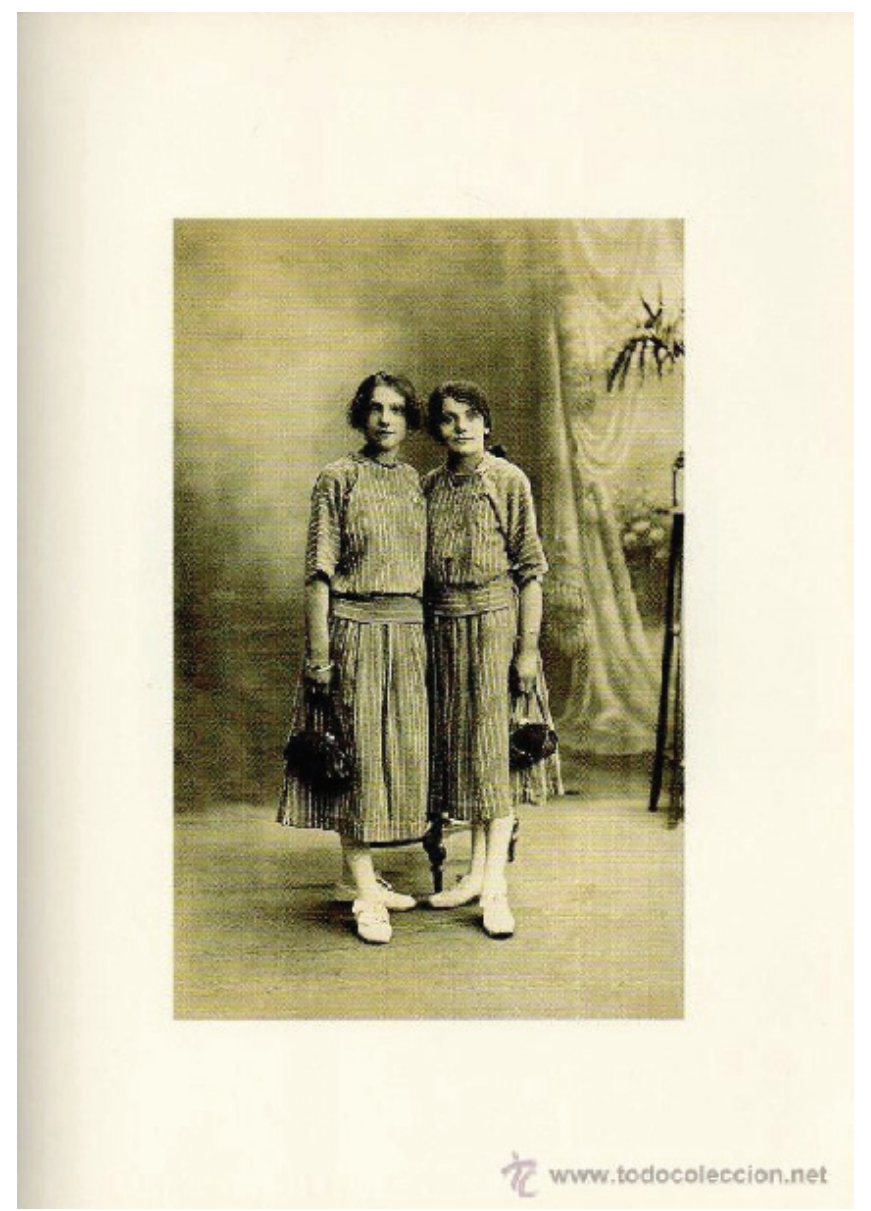

Figura 7. Mujeres, amor y mentiras, Carmela García. Imagen de foto libro.

Por último, nos referiremos a la obra de la artista Mickalene Thomas, quien también, trabajando con la reapropiación y la repetición visual, (re)articula un imaginario crítico mediante la apropiación de imágenes de la historia del arte, para reformularlas desde una posición crítica en referencia a cuestiones de racialidad y género. Para ello, en algunos de sus trabajos, la artista retomará imágenes emblemáticas de la historia del arte occidental para producir importantes desplazamientos en ellas, situando en sus imágenes a otros sujetos a menudo ausentes de las narrativas occidentales o profundamente objetualizados y exotizados en dichas narrativas. 
Así, la artista estará interesada en generar una narrativa visual donde los sujetos sean mujeres afroamericanas situadas en una posición de sujetos frente a la cámara, movilizando los códigos visuales hegemónicos de objetualización atravesados por la racialidad que tan presentes han estado en los imaginarios dominantes de la historia del arte occidental. La artista buscará, por ello, explorar las nociones de la celebridad negra, la identidad femenina y el poder.

Uno de los ejemplos de estas obras será Le dejeuner sur I'herbe: Les Trois Femmes Noires (ver figura 8), obra concebida a modo de reenactment crítico sobre la pieza histórica de Manet Desayuno sobre la hierba (ver figura 9). En la pieza original de Manet, nos encontramos una imagen de un almuerzo campestre en el que una mujer blanca desnuda acompaña en primer plano a dos varones vestidos. En un segundo plano, aparece otra mujer blanca a medio vestir ajena, aparentemente, al ojo del pintor, resaltándose así cierta mirada voyeur tan presente en el imaginario hegemónico de la tradición occidental. Por el contrario, en la pieza actualizada de Mickalene Thomas, la artista sitúa a tres mujeres negras vestidas en una escenificación que recuerda a un plató fotográfico y su teatralidad, pero que no deja de hacer guiños críticos a la obra original. En ella, las tres mujeres miran empoderadas directamente a la cámara, y se excluye a los hombres de la imagen. Así pues, si la obra de Manet refuerza la narrativa visual tradicional que objetualiza a las mujeres y las sitúa bajo la mirada del artista como acompañantes del protagonismo masculino y que articula un imaginario en torno a la belleza del cuerpo femenino blanco que cumple ciertos cánones, las mujeres de la pieza de Thomas desplazan y expanden dicho imaginario articulado sobre una mirada objetualizadora. Fuertes y atractivas, miran directamente a la cámara, empoderadas, vestidas y fuera de un discurso heteronormativo y colonialista. 


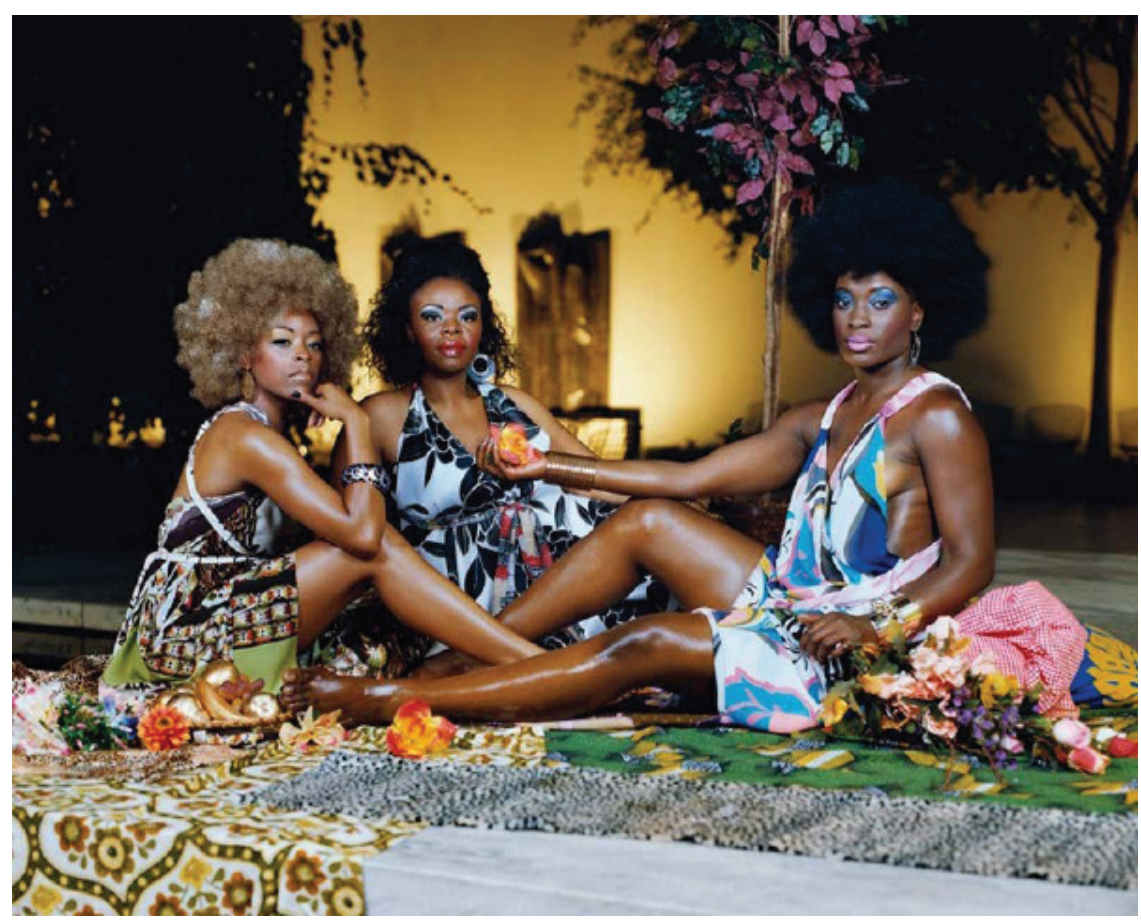

Figura 8. Le déjeuner sur l'herbe les trois femme noires, Mickalene Thomas

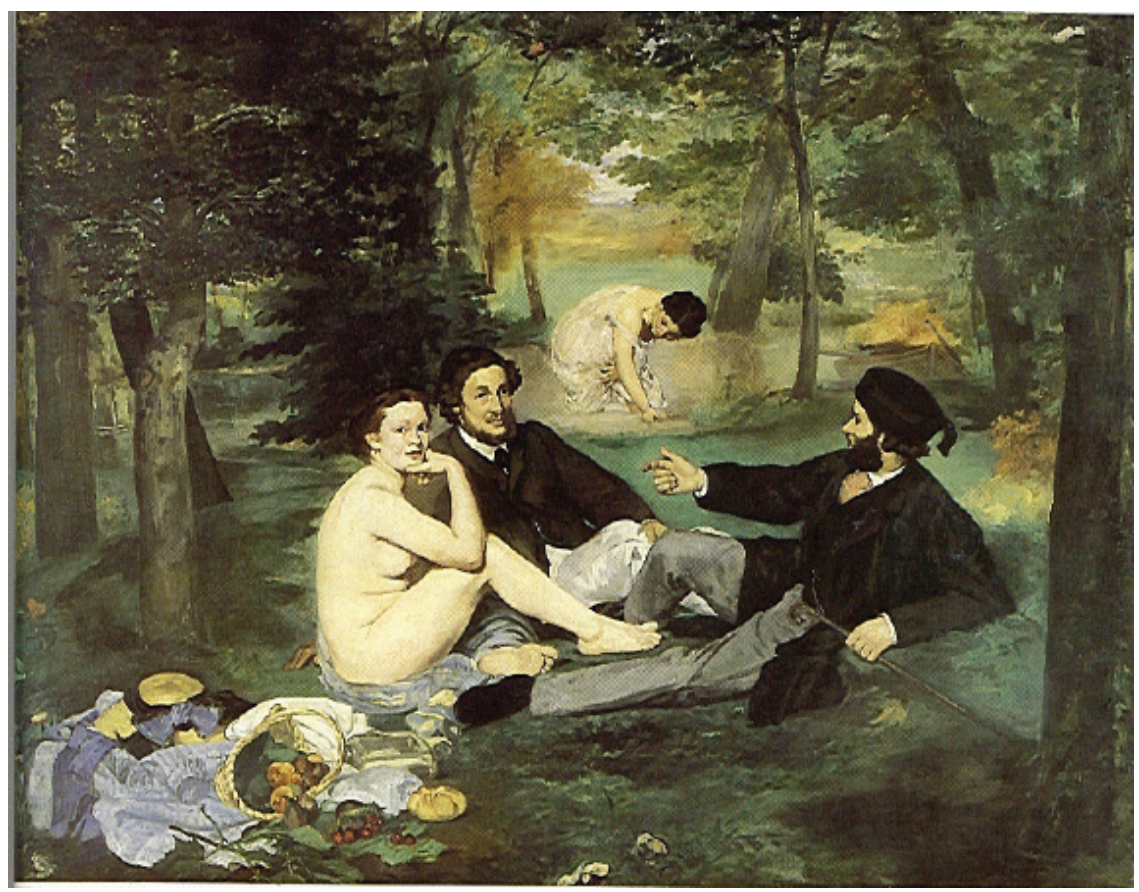

Figura 9. Desayuno sobre la hierba, Édouard Manet. 
Cuerpos, imágenes e identidades...

En otros de sus trabajos (ver figura 10), sus sujetos desplazarán (a la vez que recordarán) el imaginario dominante occidental articulado en torno a las figuras de las Venus (ver figura 11). En dichas imágenes, Thomas jugará con la memoria visual de ciertos gestos, poses y escenarios, pero provocando importantes desplazamientos al situar como sujetos de sus imágenes a mujeres negras empoderadas quienes, vestidas, miran de frente a la cámara, quienes se apropian de la forma tradicional de posar otorgada a los cuerpos leídos como femeninos y objetualizados desde la mirada del artista en esas venus icónicas del arte occidental, quienes hacen uso explícito de ciertos códigos de la sexualidad, diluyendo esas posiciones de sujeto/ objeto de la mirada, y quienes generan, por todo ello, una narrativa visual que increpa y fricciona con la dominante producida desde los cánones de la historia del arte occidental.

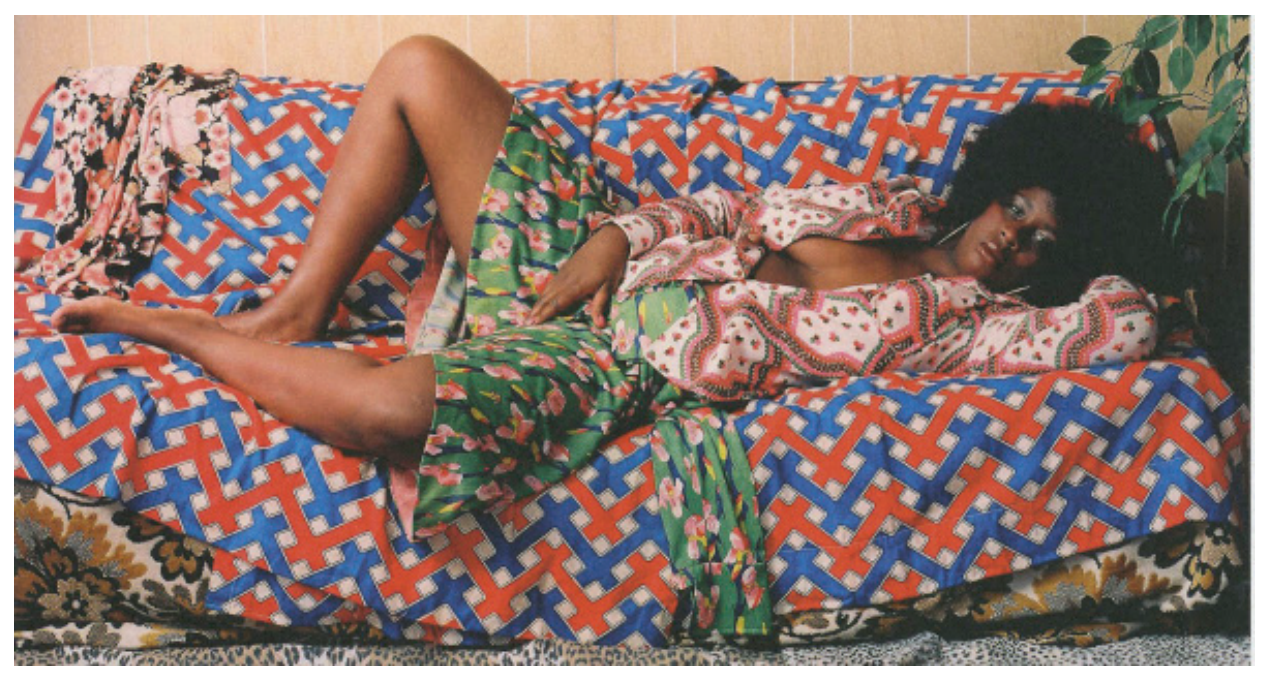

Figura 10. Afro Goddess with Hand Between Legs, Mickalene Thomas. 


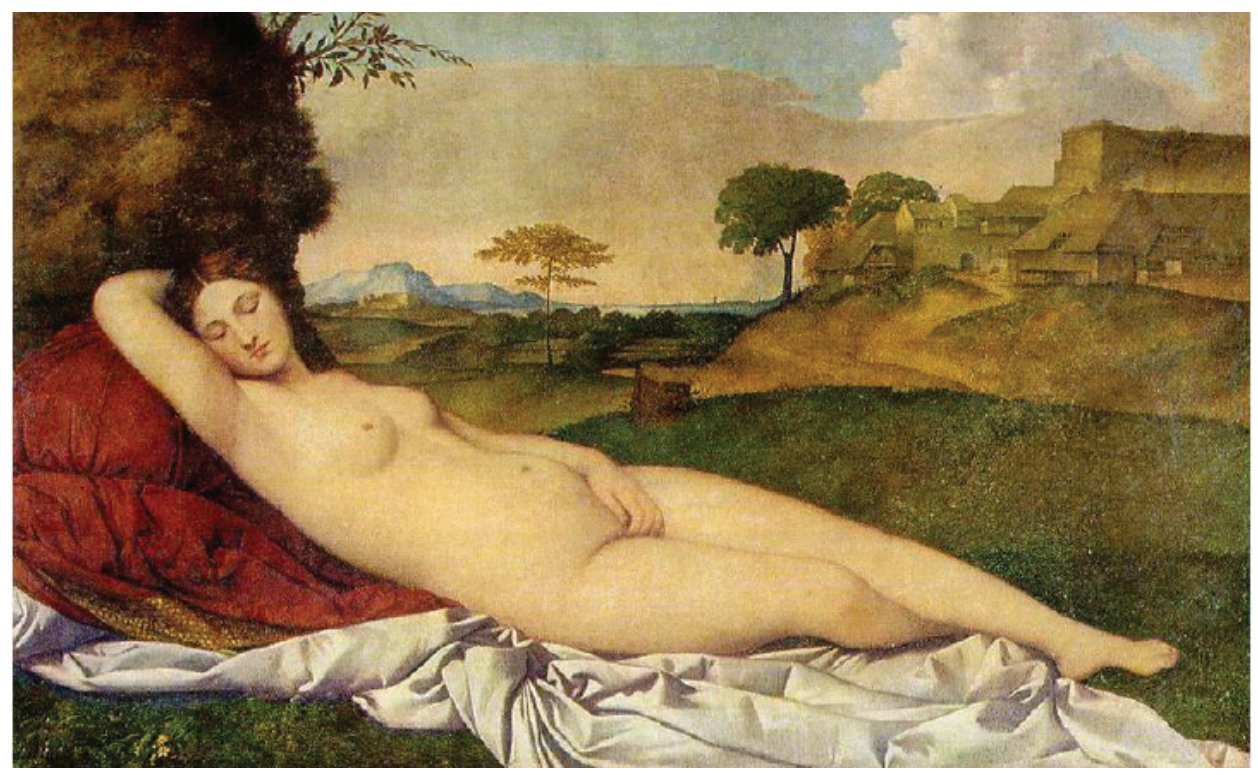

Imagen 11. Venus dormida, Giorgione y Tiziano.

Si recuperamos las imágenes analizadas, junto con el marco teórico expuesto en torno a ciertos conceptos como los de performatividad, exterioridad constitutiva o capacidad de acción de las imágenes, veremos cómo todas ellas, aunque desde distintas posiciones y perspectivas de trabajo, se (re)apropian de los archivos visuales dominantes a través de mecanismos vinculados a la repetición y la citacionalidad. Así, ya sea desde la repetición de un estilo o código formal (como en el caso de Esquivel), desde la citacionalidad de unas narrativas visuales dominantes procedentes del mundo del cine o de la historia del arte occidental (como en el caso de Cabello/Carceller o Mickalene Thomas) o directamente desde la recopilación de fotos antiguas cuya narrativa cambiará por completo tras su (re) ubicación en una nueva colección (como en la propuesta de Carmela García), todas las obras comentadas dan muestra de la capacidad de acción de las imágenes para producir nuevas realidades y dar existencia a otros relatos, sujetos e identidades que irrumpen y expanden los imaginarios dominantes. 
Estas nuevas narrativas visuales, surgidas de la repetición, la reapropiación y el desplazamiento, dan existencia a los sujetos presentes en ellas, los cuales aparecen dentro de la imagen. A su vez, estas nuevas imágenes dan posibilidad de existir a otros sujetos, espectadores y espectadoras de dichas imágenes quienes, situadas(os) fuera de ellas, pueden verse reflejadas(os) en estas, pues pueden ver allí otros modelos de identificación y existencia posible.

Así, si una de las tesis principales de las que se nutre el marco metodológico de análisis de este artículo es que la identidad es algo móvil, cambiante, que se articula performativamente y gracias a una exterioridad constitutiva, podemos concluir cómo todas estas imágenes ejemplifican dicha tesis y nos muestran ese hacer con imágenes que nos ofrece el arte y que se orientan hacia la transformación social. Todas ellas articulan, por ello, un posible contraimaginario que, desde el arte, funcionaría a modo de ese exterior constituivo que nombramos al principio de este artículo y que nos sirve para ir rearticulando nuevos mapas de lo visible y de lo vivible. En este sentido, este contraimaginario crítico, que juega con la citacionalidad, la repetición y la reapropiación, ofrece la posibilidad de identificarnos con otros modelos de cuerpos, imágenes e identidades con los que articular y negociar nuestra propia identidad en esos términos performativos de los que habla J. Butler. En definitiva, todas las imágenes analizadas conforman, así, un arte crítico, puesto que contribuyen "a la impugnación de la hegemonía dominante" (Mouffe, 2007, p. 67), cuya capacidad de acción radica en la producción de nuevas realidades contrahegemónicas conforme a las cuales, como espectadoras y espectadores, podemos articular nuestra propia identidad. 


\section{Notas}

${ }^{1}$ Me refiero aquí a la noción de performativo formulada por Austin para referirse a aquellos actos del lenguaje que en su decir producen realidad. Véase AUSTIN, J. L. (1973), How to do things with words, Oxford: Oxford University Press.

${ }^{2}$ Proyecto desarrollado por el artista desde 2007 y conformado por una serie de obras principalmente pictóricas.

${ }^{3}$ García, Carmela (2003), Mujeres, amor y mentiras, fotolibro de artista, Madrid: TF.

\section{Referencias}

Barbarelli, G. y Vecellio, T. (1510). Venus dormida (Pintura). Alemania, Galería de Pinturas de los Maestros Antiguos. Recuperado de http://aldapetarte. blogspot.com/2009/09/la-venus-dormida-de-giorgione-pintado.html

Butler, J. (2000). El marxismo y lo meramente cultural. New Left Review, (2), 109-121.

Butler, J. (2005). Giving an account of oneself. New York: Fordham University Press.

Butler, J. (2006). Precarious Life. The powers of mourning and violence. London. New York: Verso.

Butler, J. (2010). Frames of war. When is life grievable? London: Verso.

Cabello, H. y Carceller, A. (2011). Archivo: Drag Modelos (Exposición de fotografía). España, Las Palmas de Gran Canaria, Centro Atlántico de Arte Moderno (CAAM). Recuperado de http://www.caam.net/es/galerias_ int.php? $=61$ 
Cortés, J. M. (2000). Introducción. En H. Cabello, A. Carceller, D. Cameron, A. Martínez y A. Navarrete, Zona F. Una exploración sobre los espacios habitados por los discursos feministas en el arte contemporáneo. (Catálogo de exposición). Castelló: EACC.

Esquivel, A. (2014). Memorial Garden (Exposición de arte). España, Las Palmas de Gran Canaria, Centro Atlántico de Arte Moderno (CAAM). Recuperado de http://www.alexisesquivel.com/index.php/seleccionprevia-de-obras/

Fernández, A. (2012). Usos performativos de las imágenes. En Re-Visiones, (2), 1-5. Recuperado de: http://www.re-visiones.net/index.php/RE-VISIONES/ issue/view/9

Garbayo, M. (s.f.). Estrategias estéticas. REVISTA PIPA, (3), 18-27.

García, C. (2003). Mujeres, amor y mentiras (Fotolibro de artista). Madrid: TF.

Manet, E. (1863). Le Déjeuner sur l'Herbe [Desayuno sobre la hierba] (Pintura). Paris, Museo de Orsay. Recuparado de http://www.manet.org/luncheonon-the-grass.jsp

Mouffe, C. (2005). On the political. New York: Routledge.

Mouffe, C. (2007). Prácticas artísticas y democracia agonística. Barcelona: MACBA.

Mouffe, C. (2009). Feminismo, democracia pluralista y política agonística. Debate Feminista, 40, 86-99.

Pérez, P. (2007). Márgenes del género: Judith Butler y la deconstrucción. En C. de Peretti y E. Velasco (Eds.), Conjunciones. Derrida y compañia (pp. 357381). Madrid: Dykinson.

Ranciére, J. (2010). El espectador emancipado. Castellón: Ellago. 
Sánchez, S. (2015). La pintura de historia en la perspectiva postcolonial. Entrevista a Alexis Esquivel. Arte y políticas de indentidad, 13, 271-286.

Thomas, M. (2006). Afro Goddess with Hand Between Legs (Impresión cromogénica). Chicago, Galería Rhona Hoffman. Recuperado de https:// www.phillips.com/detail/MICKALENE-THOMAS/NY040315/32

Thomas, M. (2010). Le déjeuner sur l'herbe: Le Trois Femme Noires (Fotografía). Estados Unidos, Seattle Art Museum. Recuperado de https://www.artsy. net/artwork/mickalene-thomas-le-dejeuner-sur-lherbe-les-trois-femmesnoires-2

Vogel, F. (2011). El rostro de Antu. O de Agata, Cole, Desislava, Dina, Emily, Joanna, Katia, Mihaela, Lisa, Sam o Toni. Acerca de Archivo: Drag Modelos de Cabello/Carceller. En Cabello/Carceller. Archivo: Drag Modelos. (Catálogo de exposición). Las Palmas de Gran Canaria: Centro Atlántico de Arte Moderno (CAAM). 